\title{
The Effect of Teaching Reading Strategies on the Students' Motivation to Read in English
}

\begin{abstract}
The present study aims at investigating the effect of teaching reading strategies to non motivated readers on their motivation to read in English. It is based on the hypothesis that some students lack motivation to read in English due to their employment of inadequate reading strategies, and that if they are trained in the use of more effective ones, then this motivation will subsequently increase. To test these hypotheses, a first questionnaire is administered to all first year students of English at the Teacher Training School of Constantine in order to identify the non motivated ones and the cause(s) of this lack of motivation. Instruction on more effective reading strategies is then provided to fourteen students among the non motivated ones. At the end of this instruction, a second questionnaire is administered to these students to determine its success in enhancing their motivation to read in English.
\end{abstract}

\section{Sorya MEZHOUD}

Faculty of Letters and Languages Department of Foreign Languages University of Mentouri Constantine (Algeria)

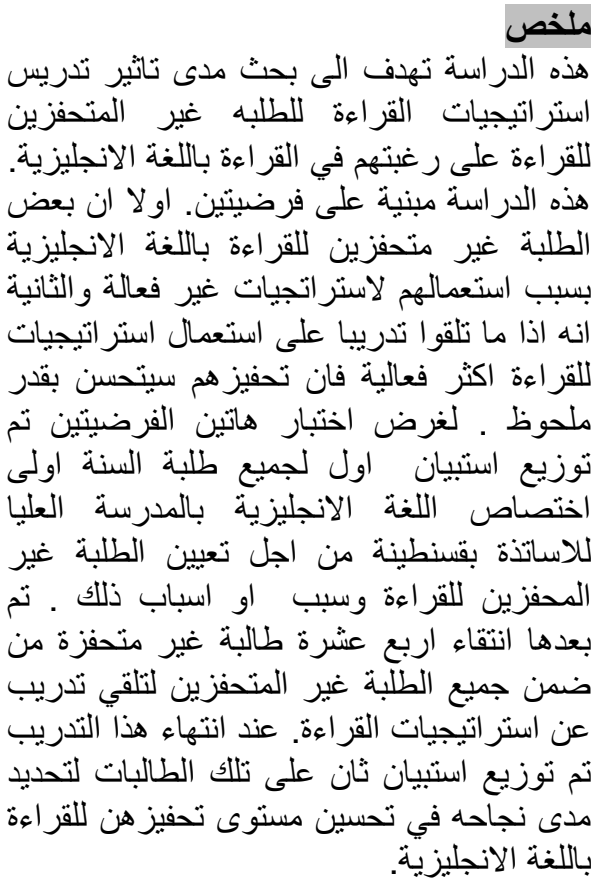

\section{Introduction}

Reading Techniques is a subject taught at the Teacher Training School of Constantine. Its objectives are to instil in the students the habit of reading and to teach them reading comprehension strategies. However, throughout the many years they have been teaching this subject, teachers have found that students do not read unless they are required to do so. Many students lack motivation to read.

(c) Université Constantine 1, Algérie, 2015. 
The present article aims at investigating the possible cause(s) of lack of motivation to read in English. It is based on the hypothesis that many students lack motivation to read in English because of their use of ineffective reading strategies that do not help them in text comprehension. It is also based on the hypothesis that if students are taught effective reading strategies, then their motivation to read in English will increase.

To test the above hypotheses, a questionnaire is administered to 80 first year students at the Teacher Training School of Constantine to discover what causes lack of motivation to read in English among students. After the cause(s) is/are discovered, the non motivated students will be identified, and a focus group is selected among them to receive instruction on reading strategies that would help them to read better and therefore become more motivated readers. To check the success of the instruction in increasing the students' motivation to read in English, the same questionnaire administered prior to the instruction, is handed in again to the non motivated students. First year students are selected to undergo this study because this is the first time they are exposed to a reading course in English, and therefore they are unlikely to possess effective reading strategies.

\section{Reading Strategies}

Reading is an essential skill in the learning process of any language and even outside academic contexts. Many requirements are needed in the reading process, namely adequate mastery of vocabulary and grammar as well as some reading strategies which contribute to improving the reading ability.

Reading is described as a psycholinguistic guessing game in which readers make predictions by relying on general knowledge of the world to make intelligent guesses about what might come next in the text and then they sample just enough of the text to confirm or reject these guesses (Goodman, 1979). This guessing game is a complex activity, especially when reading in a foreign or a second language. Reading is in fact a complex skill because four factors are involved in reading comprehension (King, 2008): the reader, the text, the strategies, and the goal. Among these factors, reading strategies are the most important ones, as King has emphasised.

Reading strategies are defined as the mental operations that readers use to process a text effectively and to give it sense (Barnett, 1988:66). Another definition is the one provided by Karami (2008) who claims that reading strategies are the conscious, internally variable psychological techniques aimed at improving the effectiveness of reading comprehension or compensating for the breakdowns therein.

Reading strategies exert a major impact on any act of reading. In this context, King (2008) emphasised that reading strategies are what makes the difference between poor and good readers. Accordingly, Lau (2006) claimed that good readers are those who use better learning strategies while poor readers either give up easily when they face problems or they use inefficient strategies. On the other hand, Hosenfeld (1977) maintained that the "unsuccessful" foreign language reader loses the meaning of sentences as soon as they are decoded, read in short phrases, seldom skip words as unimportant, view words as equal in their contribution to total phrase meaning and has a negative self-concept as a reader. 
On the other hand, Pearson and Gallagher (1983) argued that better readers are those who have a better ability to summarize and make effective use of background knowledge. In addition to that, they employ the structure of the text, make inferences, and are aware of the strategies they use. Generally, they monitor and adjust better the strategies they use; and therefore, the better readers are more strategic. This means that they have purposes for their reading and adjust their reading to each purpose and for each reading task. Strategic readers use a variety of strategies and skills as they construct meaning. For Hosenfeld (1977), good readers are the ones who attempts to keep the meaning of what they read in mind, read in chunks, ignore less important words, try to guess the meaning of unknown words by relying on contextual clues, and have a good concept of themselves as readers.

Studies of strategy use have yielded quite consistent descriptions of the tactics employed by second language readers to interact successfully with target language texts. For example, Saricoban (2002), who used a questionnaire to determine strategy use, found that successful readers engaged in predicting and guessing, accessed background knowledge related to the topic of the text, guessed the meaning of unknown words, reread the entire passage, identified main ideas and monitored comprehension; in other words, successful readers employed global top-down strategies that were cognitive, metacognitive and compensatory in nature. Poor readers, on the other hand, tended to process text on a word-for-word basis, focusing on grammatical structures, sound-letter correspondences, word meaning, and text details. Barnett (1989) found that less effective readers focused on meaning of individual words, paid attention to text structure, reread isolated sentences or passages rather than the entire text, never or rarely hypothesised and resisted skipping any unknown words. On this basis, he concluded that, less skilled readers tend to employ local, bottom-up strategies, whereas more successful readers use global, interactive and metacognitive reading strategies. Block (1986) also found that general comprehension strategies (anticipating content, recognising text structure, integrating information, questioning information, distinguishing main ideas from detail, monitoring comprehension, correcting behaviour, focusing on textual meaning as a whole and reacting to the text) were superior to local linguistic strategies (rereading words or sentences, questioning the meaning of words or sentences and solving vocabulary problems).

Many lists of reading strategies have been investigated and suggested by many researchers. Gascoigne (2008) for instance, suggested that the most commonly-cited reading strategies include skimming, scanning, identifying cognates or word families, guessing, reading for meaning, predicting, questioning, rereading words/ sentences or entire passages, activating general or background knowledge, making inferences, following references, separating main ideas from detail, and summarising. Other researchers (Harris 1997, Brown 2001, Kennedy 2003) suggested other lists of reading strategies,

\section{Strategy Training}

On the basis of the observation that some students are better learners than others, it is assumed that less successful learners could be helped by teaching them to use the strategies employed by the more successful learners. In this respect, Grenfell and 
Harris (1999) argued that if successful learners possess a larger repertoire of strategies than the less successful ones, then a judicious decision would be to intervene and offer them the chance to learn these tools. It could also be argued that explaining explicitly to students how to deal with the learning process is not only likely to increase such learners' range of strategies, it might also enhance their motivation.

Although no empirical evidence has yet been provided to determine a single best method for conducting strategy training, at least four different teaching approaches, (Pearson and Dole (1987), Oxford et.al.' (1990), Chamot and O'Malley (1994), and Grenfeld and Harris's (1999)) have been identified. Each one has been designed to raise students' awareness of the purpose of strategy use, to give students opportunities to practise the strategies they are being taught and help them use the strategies in new learning contexts (Cohen: 1998). The four approaches share many similarities in regard to the broad stages of the training. It is possible, thus, to note the existence in all of them of a stage of preparation where the trainer helps the learners discover the strategies they already possess. There is also a stage of presentation where the trainer demonstrates other new strategies emphasising their potential benefits. Still another common stage is that of practice where the learners are offered opportunities to practise the new strategies. Finally, all approaches include a stage of evaluation in which the teacher guides learners to evaluate progress and strategy use.

\section{Motivation to Learn a Second/Foreign Language}

New pedagogical and methodological orientations attribute a great importance to motivation as being the surest basis for every learning activity in general, and a greater importance as far as language learning is concerned, in particular, because it involves communicating with others. Most language teachers and writers in the field of psychology of learning agree that motivation is a prerequisite for success in language learning. In that respect, Corder (1967: 164) said, 'Let's say that, given motivation, it is inevitable that a human being will learn a second language if he is exposed to the language data'. So, if learners are highly motivated, they can always achieve something meaningful even if other factors in the learning process are less than ideal. But if motivational levels are low, teaching will be a difficult struggle and achievement levels will be disappointing.

Another definition is the one provided by Brown (1994: 152) 'Motivation is regarded as an inner drive, impulse, emotion or desire that incites one to perform a particular action. It refers to what experiences or goals a person decides to approach or avoid, and to what extent he will exert an effort in that direction'.

Gardner (1985; cited in Dornyei, 1998:122), who claimed that motivation is 'the extent to which an individual works or strives to learn the language because of a desire to do so and the satisfaction experienced in this activity' subsumed that motivation is underlied by three components: motivational intensity, desire to learn the language and an attitude toward the act of learning the language. Therefore, Gardner's theory suggests that motivation is somehow a mental engine that subsumes effort, want/will (cognition) and task-enjoyment (affect). According to him, the three components are necessarily bound together to form the true sense of motivation. 
In addition to this, attention to input is a crucial component of motivation. In this respect, Schmidt (1990; cited in Crookes and Schmidt 1991) contended that a necessary condition for language learning to take place is attention to input, and that what becomes intake is what learners are attentive to. There is a close relationship between attention and motivation because definitions of motivation refer to attention and persistence as the behavioural manifestations of motivation.

A large scale of studies has been carried out on the role of motivation and attitudes in second language learning, and both teachers and researchers have long recognised the importance of these two affective factors in the process of acquiring another language. Crookes and Schmidt (1991) contended that the major approaches to the study of the role of motivation in learning a second language are social and psychological and that they are based to some different degrees, on two common features: motivation and attitudes. In this line of research, motivation has always been linked to attitudes towards the speakers of the target language, to the desire to interact with these speakers, and to a certain level to self-identification with the target language community. The underpinnings to research in this field, in fact, had been provided by Gardner and Lambert and their associates in Canada in the 1950's. Their work stipulated that interest in learning another language often develops as a result of emotional involvement with the other language community or because of a direct interest in the language itself. The line of inquiry that continues until nowadays has had a significant effect on the understanding of foreign language learning.

A major principle of Gardner and Lambert's social educational approach in Canada is that attitudes towards the second language community strongly influence one's second language learning. The model also assumes that learners' goals fall into two broad categories, integrative motivation and instrumental motivation. According to Gardner et. al. (1976: 199) integrative motivation is 'a high level of drive on the part of the individual to acquire the language of a valued second language community in order to facilitate communication with that group'. The learner is also said to have this type of motivation when he wishes to identify with the culture and speakers of the target language. On the other hand, a learner is said to have instrumental motivation when he needs the language for functional reasons as passing an examination, increasing job opportunities or facilitating the study of other subjects through the medium of the target language.

However, many researchers do not agree that one always learns a second language because we want to become part of the L2 community or because we want to get a better job or increased salary. This implies that other types of motivation may underlie different actions. Alternative motivations to the integrative/instrumental dichotomy are the intrinsic/extrinsic orientations. In this respect, Deci and Ryan (2000) distinguished between two types of motivation based on the different reasons or goals that energize an action. These are intrinsic motivation which refers to doing something because it is inherently interesting or enjoyable, and extrinsic motivation which refers to doing something because it leads to a separable outcome. Research in this field has shown that the quality of experience and performance can be very different when one is behaving for intrinsic versus extrinsic reasons. Interest is considered as a main element 
in both intrinsic and extrinsic motivation. It is the positive response to stimuli in such a way that learners' curiosity is aroused and sustained.

Many factors may hinder learning and therefore negatively affect motivation. One of such factors is language anxiety. It is the fear that individuals feel when they have to use a second or foreign language in which they are not fully proficient. It is characterised by derogatory self-related cognition, for example, a feeling that one cannot do a certain task. Gardner and MacIntyre (1993) define anxiety as 'the apprehension experienced when a situation requires the use of a second language with which the individual is not fully proficient'. They consider language anxiety as a stable personality trait related to the individual's tendency to react nervously when speaking, listening, reading or writing in the second language.

Anxious students have been shown to be less likely to volunteer answers in class to be hesitant in expressing personally relevant information in the target language as reported by MacIntyre and Gardner (1989) who have explained the negative effect of anxiety on second or foreign language learning by the fact that anxiety deviates attention and cognitive resources that could otherwise be effectively used to improve performance in the second language. Moreover, it is claimed that the more anxious the learners are, the less proficient in speech skills they are (Gardner et.al. 1976). The consideration that language anxiety has a negative effect on second or foreign langue learning can lead to the generalisation that it also negatively affects the students' motivation to learn languages. Gardner and MacIntyre (1993) contended that language anxiety and motivation are two variables which tend to be negatively correlated.

\section{The Students' Motivation to Read in English}

In our study, the first questionnaire, made of eight questions, is administered to 80 first year students at the beginning of the second term in order to give sufficient time to the students to get acquainted with the reading techniques course, the teacher, and with reading in English. The aim of this questionnaire is to identify the students who are not motivated to read in English and what this lack of motivation is due to. The non motivated students will be presented with some reading strategies which will constitute the core of the instruction that aims at creating in them motivation to read in English.

The first question asks the students if they like to learn English. This is related to their attitude towards learning English since there is a linear relationship between attitudes, motivation and second language learning in that attitudes affect motivation, which in turn affects second language learning. A large majority of $96.25 \%$ representing 77 students have declared that they like to learn English whereas only $3.75 \%$ representing 3 students have stated that they do not. This is understandable enough as almost all students who have chosen to enrol in the English department of the Teacher Training School are genuinely interested in learning English and in becoming English teachers. This is confirmed by their responses during the entrance interviews they have to take before they enter the school and by the high scores they had obtained in English in the baccalaureate examinations. Very few students are exceptions to this fact, as they choose to study English for no other reason than the prospect of the future job or in compliance with their parents' or other influential 
people's desires. This may account for the fact that three students out of the total population of the study have declared that they do not like to learn English. This may negatively influence their attitudes towards the different courses in general and towards reading in English in particular.

The second question asks the students if they hate reading in English. In fact, attitudes towards the target language, the learning situation and the activities related to it, including reading, are part of the motivational construct. The majority of the questionnaire respondents, $65 \%$ representing 52 students have declared that they do not hate reading in English and 35\% representing 28 students have stated that they do. In comparison to the previous question about attitudes towards learning English, more students hate to read in English. It seems that some students like to learn English but hate to read in this language and analysis of the following questions will attempt to explain this. Because the objective of the present article is to find out the reason(s) of lack of motivation to read in English, focus will be put on this category of students. Therefore, they are required to explain why they hate English; however, only 14 of them have done so. Their answers are the following:

a- I hate using the dictionary each time to see the meaning of difficult words. (5 students have given similar answers)

b- Because sometimes I find the language difficult and I can't understand it. (2 students have given similar answers)

c- Because sometimes I find many words that I can't understand, so I give up. (1 student)

d- When I read and I don't understand a word I can't carry on. This really disturbs me. (1 student)

e- I find difficulties because they use difficult words. (1 student)

f- Because I feel afraid when the teacher asks me to read especially that I haven't enough self-confidence when I face unfamiliar words and I have always the idea that I will not read in a good way. (1 student)

g- It is boring because I spend a lot of time to understand every word. (3 students have given similar answers)

Examination of these answers reveals that such students hate to read in English not because of their attitudes towards English since most of them have already declared that they like to learn English in the previous question. This is rather mainly attributed to their inability to use adequate reading strategies. In fact, they show characteristics of poor readers. This is confirmed by Lau (2006) who contended that poor readers give up easily when they face problems or they use inefficient strategies. In addition, Hosenfeld (1977) explained that poor foreign language readers lose the meaning of sentences as soon as they are decoded, read in short phrases, seldom skipped words as unimportant, viewed words as equal in their contribution to total phrase meaning and had a negative self-concept as readers. This is exactly what the unmotivated students in this study do. They give up easily because they find words difficult (answers a through e), lack selfconfidence as readers (answer f) and get easily bored (answer g) probably as a result of inability to deal with the text appropriately. 
The third question asks the students if they think that reading in English is boring. Only $31.25 \%$ representing 25 students have declared that they think so, whereas $68.75 \%$ representing 55 students have stated that they do not. The results obtained show that almost the same number of students who have declared that they hate to read in English in the previous question have stated that reading in English is boring. This may stand as the explanation for this negative attitude. This boredom could be the result of ineffective teaching techniques, unappealing reading materials and activities that do not respond to the learners' interests and needs. More specifically, it could be the result of the students' lack of appropriate reading strategies that would enable them to process reading materials in such a way as to make sense of them and appreciate them better. This is confirmed by the students' justification of their answers to the second question where they have explained the fact that they hate to read in English by reasons that reveal employment of ineffective reading strategies. This has generated lack of motivation to read in English.

The fourth question asks the students if they have a strong desire to read in English. A total of $33.75 \%$ representing 27 students have claimed that they do not have such a desire, while $66.25 \%$ representing 53 students have maintained that they do. The results obtained for this question have confirmed those obtained for the previous one. In fact, the students who hate to read in English have also shown no desire to do so. Indeed, desire to learn a language and to perform activities related to it, in this case reading in English, is among the constructs which constitute motivational intensity along with attitudes towards learning that language. At this point, it is worthwhile to refer back to Ryan and Deci's (2000) distinction between intrinsic and extrinsic motivation. The twenty seven students who have declared that they do not have a strong desire to read in English do not consider reading in English interesting for its own sake. Whether learners behave for extrinsic or intrinsic reasons can significantly affect their performance.

The fifth question asks the students if they really enjoy reading in English. Only $35 \%$ representing 28 students have declared that they do not, while $65 \%$ representing 52 students have maintained that they do. The answers to this question strongly confirm those to the previous one, as almost the same number of students, and in fact the same students except for two have reiterated the answers they have expressed in the fourth question. When one does not have a strong desire to perform an activity, one will certainly not enjoy doing it when one has to do so. In fact, desire to accomplish a task and the enjoyment felt while doing this are constituents of motivation (see Gardner's 1985 definition of motivation, p4). This question also shows that these 28 students have no intrinsic motivation to read in English since they do not consider this activity an interesting or an enjoyable one. This could be intensified by their lack of appropriate reading strategies that would help them deal with reading materials since most students who have stated that they hate reading in English (question 2), have justified this by difficulties encountered at the word level; i.e. their inability to understand difficult words causes them to lose sight of the whole meaning and eventually to give up reading. 
The sixth question asks the students if they tend to give up and not pay attention when they don't understand what they are reading. Only $26.25 \%$ representing 21 students have stated that they do and $73.75 \%$ representing 59 percent have declared that they do not. Brown (1994) who maintains that motivation is regarded as an inner drive, impulse, emotion or desire that incites one to perform a particular action, has included an important aspect of motivation in his definition of this construct which is the effort exerted in the direction of the experiences or goals a person decides to approach or avoid. In relation to the factor of attention, Schmidt (1990, cited in Crookes and Schmidt 1991) contended that a necessary condition for language learning to take place is attention to input, and that what becomes intake is what learners are attentive to. There is a close relationship between attention and motivation because definitions of motivation refer to attention and persistence as the behavioural manifestations of motivation. Therefore, it is obvious that absence of effort, attention and persistence are signs of absence of motivation. This is shown through the answers of 21 students of the total population who have claimed that they tend to give up and not pay attention when they do not understand what they are reading. These students are among the non-motivated population of the study and they were requested to justify their answers. Only 12 of them have done so and their answers are reproduced in what follows:

a. I would like to understand all what I am reading or it will be a waste of time.

b. I get tired of using the dictionary and looking for words.

c. I find difficulty to understand the meaning of many difficult words.

d. When I don't understand what the book is talking about, I feel like I am bored so I just give up and choose another one.

e. Because I feel bored when I have to use the dictionary when I find a difficult word.

f. Because when I can't read in a good way or don't understand the meaning of the content I feel bored and I give up.

g. I get bored.

h. I get bored and I feel that I am not good.

i. Because I feel that I have no level that enables me to carry on.

j. When I read historical or scientific texts.

k. Because I don't have time to read, I have other things to do.

1. Because I want to learn new vocabulary.

Examination of these answers shows that they are similar to the justifications given by students who have declared that they hate reading in English (Q2). Reasons that account for students' lack of attention and persistence to read are related to the use of inappropriate strategies. The respondents tend to believe that all words are equally important for comprehension, do not skip unnecessary words and tend to rely heavily on the dictionary. They consequently feel bored and eventually give up. They also lack self confidence. In short, they display characteristics of unsuccessful readers (Hosenfeld, 1977). 
In the seventh question the students are asked if they get anxious when they have to answer questions in their Reading Techniques class. A total of $42.5 \%$ representing 34 students have declared that they do while $57.5 \%$ representing 46 students have stated that they do not. Language anxiety is the fear experienced by individuals who have to use a second or foreign language which they do not fully master ( see Gardner and McIntyre, 1993 above, p5). High levels of motivation can decrease language learning anxiety, but on the other hand, increased anxiety negatively affects motivation to learn a foreign language and to practice it. The number of the students who have maintained that they get anxious when they have to answer questions in their Reading Techniques class is only slightly higher than the number of the unmotivated students identified in the previous questions and this increase can be due to the combined stress of reading and speaking in front of the whole class. It can be claimed, therefore, that reading class anxiety is either the cause or effect of lack of motivation to read in English. The students who have provided this answer were required to explain it and only 19 students did so. Their answers are summarised as follows:

a. Because reading in English is difficult. (8 students)

b. Because of difficulties to understand. (5 students)

c. Because of fear of making mistakes. (4 students)

d. Because of the teacher. (2 students)

The answers given by the students reveal that their anxiety is due to lack of mastery of the reading skill in English (answers a and b), fear of making mistakes (answer c) or fear of the teacher's reaction (answer d). Analysis of earlier questions has already indicated that unmotivated students have developed negative attitudes towards reading in English mainly because of the difficulties they have experienced with reading comprehension. They need to understand every single word using the dictionary and eventually give up reading as this task, which is too demanding, obviously hampers their comprehension of the general meaning and reduces their ability to answer questions. This difficulty is mainly related to the use of inappropriate reading strategies and ignorance of more effective strategies. Fear of making mistakes (answer c) is another reason for feeling anxious that four students have given. The definition of language learning anxiety given above refers to the fear experienced when a learner has to use a language which he/she does not fully master. So students who have difficulties to understand reading materials develop anxiety to read and to answer questions in the reading class. It seems that these students are much more concerned with receiving positive judgements about their behaviour than with learning itself. On the other hand, students whose goal is to learn will not hesitate to take part in activities even if they are likely to make errors. Both behaviours are related to motivation or lack of it. In addition to that, it is also possible to claim that these students have developed the impression that they cannot achieve success in reading due to repeated failures. Finally, two students have explained their anxiety by the fear of the teacher's reaction. Obviously, when teachers do not adopt a supportive, encouraging and motivating attitude towards their students, or when they give more importance to correct performance than to learning itself, they might intimidate them and even hamper their motivation to learn and to practice the language. 
In the eighth and last question of the questionnaire, the students are asked if they feel very much at ease when they have to read in English. A majority of $68.75 \%$ representing 55 students have declared that they do while $31.25 \%$ representing 25 students have stated that they do not. The number of the students who have declared that they do not feel at ease when they have to read in English is slightly inferior to the number of those who have already declared that they feel anxious when they have to answer questions in the reading techniques class. This might be attributed to the nature of reading as solitary activity compared to answering questions in front of the whole class. Some students feel more at ease when reading alone than when they have to answer questions. But still this number (25 students) is close to the number of the unmotivated students already identified. It can be restated that these students' motivation is either the cause or effect of anxiety.

The second part of this question requires the students to say why they do not feel very much at ease when they have to read in English and 13 of them have given the following answers:

a. Because I will be obliged to understand every single word.

b. Because I need to check the meaning of many words in the dictionary.

c. Because of the difficult words.

d. New difficult words.

e. Because I can't benefit from any reading when I read something difficult.

f. I can't understand everything that I am reading and sometimes I feel lost when I cannot understand every word.

g. Because I find a lot of difficult words.

h. I find some difficulties.

i. Sometimes I need a lot of time to understand the meaning.

j. I have some difficulties to understand some words and expressions.

k. Most teachers asked us to read novels but I hate reading them, they seem boring and I prefer to read real topics but I don't know where to find them.

1. I have some pronunciation problems.

m. Because I have a slow reading rate.

The explanations given by the students to explain their answer to this question corroborate the ones they have given to explain the previous question. They also correlate with the students' complaints about their inability to deal effectively with vocabulary and felt need to understand every new word (questions 2 and 3). Most of the students who have answered this question have explained it by the difficulties they face vis à vis unfamiliar vocabulary. Their inability to use effective reading strategies in order to interact successfully with texts and their focus on word to word analysis is a problematic issue which has proved to cause the students to feel helpless and to give up reading. In the present question and the previous one, it has also proved to be the origin of the students' reading anxiety and therefore, the cause of their demotivation to read in English. 
The analysis of this questionnaire has made it possible to identify a population of 28 students who lack any motivation to read in English, and who have declared that they hate to read in English. Since the present study is concerned with exploring causes of lack of motivation to read in English, focus is put on this category of students. For the sake of the present study, a focus group made of 14 students is selected to receive instruction on reading strategies.

After examining the reasons underlying such a negative attitude towards reading in English, it is found out that they are mainly due to the employment of ineffective reading strategies that lead to boredom and eventually to cause those students to abandon reading (question 2). Such ineffective reading strategies are mainly related to the desire to process texts at the word level rather than whole section level, leading the students to want to understand every new word using the dictionary. As this is obviously a tedious and boring act, the students eventually give up reading. This has further been confirmed by the non motivated students' answers to question three when they explained the reason why they tend to give up and not pay attention when they do not understand what they are reading by reasons related to the extensive use of the dictionary out of a need to understand the meaning of unfamiliar words and the ensuing boredom resulting from this. Such students have reiterated the same reasons to explain why they do not feel much at ease when they have to read in English (question 5).

The analysis of the questionnaire has also revealed that the unmotivated students identified in this study feel anxious when they have to answer questions in the reading class and when they have to read in English. Most of those who had to justify their anxiety attributed it to difficulties encountered at the word level and a desire to understand every new vocabulary item.

Therefore, it can be claimed that the first hypothesis which states that the students' lack motivation to read in English is due to the use of ineffective reading strategies has been confirmed.

\section{Instruction on Reading Strategies}

The instruction that the 14 students have undergone follows the four stages of training that the four approaches of strategy training (mentioned above, p3) share in common, namely preparation, presentation, practice and evaluation.

\section{a. Preparation}

In this stage, the students are given a text and asked to read it and to reflect on the strategies they have used in order to understand its content. They are encouraged to recall any useful strategies that they might have already acquired through previous schooling even if these strategies are used in reading in another language. They are also asked to explain how the strategies they have used have facilitated their reading comprehension. After reading the text, the class has engaged in a brainstorming session where the students have claimed to have used the following strategies:

1. Using the dictionary to explain difficult words, (mentioned 11 times)

2. Rereading sentences, (mentioned 9 times) 
3. Rereading the introductory sentences to have a better idea of what the text was about, (mentioned only once).

4. Relying on the title of the text to predict its content, (mentioned only once).

5. Relying on context clues to guess the meaning of difficult words, (mentioned only once).

6. Skipping difficult words and continuing to read. (mentioned only once).

This brainstorming has revealed that the students have made use of a very limited range of strategies and that, as was expected and already revealed through the first questionnaire results, the most recurrent strategy among most of the students is the use of the dictionary to explain difficult words (11 students among 14 have declared that they have used it). Rereading sentences, is another strategy that focuses on local meaning of separate sentences rather than whole text meaning and it is mentioned by 9 students. However, the students who have mentioned relying on the title of the text to predict its content, relying on context clues to guess the meaning of difficult words and skipping difficult words and continuing to read (they are three) have pointed at strategies that go beyond the word level to be rather concerned with general comprehension. Nonetheless, the fact that they have mentioned only a very limited range of reading strategies (only one strategy for each student) does not allow one to consider them successful readers because a successful reader is the one who uses better strategies than the unsuccessful one both in terms of quantity and quality.

On the whole, and disregarding the three last strategies, the type of strategies used by the students reveals that they are unsuccessful foreign language readers (which should not be mistaken for unsuccessful foreign language learners). That is, they tend to deal with texts on a word-for-word basis, focusing on sound-letter correspondences, word meaning, and text detail. They also reread isolated sentences or passages, rather than the entire text, and resist skipping any unknown words (except for one student). In other words, these students tend to employ local, bottom-up strategies which are less efficient than global, top down strategies that rather focus on general comprehension.

This discussion being made, it is then possible to mention the criteria of selection of reading strategies that will constitute the core of the instruction:

1. The students' answers to the questionnaire that have revealed that their dislike of reading in English is due to lack of comprehension of difficult vocabulary items and their useless struggle with defining them using the dictionary.

2. The type of reading strategies they have used in dealing with the text during the preparation stage which confirmed their extensive use of the dictionary as a main strategy to get meaning through.

3. Reference to the review of the literature that maintains that bottom-up strategies that focus on questioning the meaning of words and on vocabulary problems rather than general meaning are used by unsuccessful readers.

On this basis, the strategies that are selected for the instruction will teach the students:

1. How to deal with vocabulary without necessarily using the dictionary,

2. How to approach global understanding of text, 
3. To use a combination of effective strategies to comprehend texts.

The strategies suggested for this training are skipping unnecessary words, guessing the meaning of vocabulary from the context, scanning and skimming, paraphrasing and restatement, distinguishing main ideas from detail, questioning and previewing. The instruction will last for fifteen weeks, one hour and a half per week.

\section{b. Presentation and Practice}

A decision is made to integrate these two stages together because it is judged more appropriate to follow the presentation of each strategy with immediate practice. Therefore, a theoretical presentation where each strategy and the importance of its use is made followed with extensive practice. Since it cannot be assumed that students will make use of these strategies simply by being told about them, constant reminders to use certain strategies are made. Before a new strategy is introduced, review of the previous one is made and the students are constantly reminded that when dealing with every new activity it is necessary to integrate all the previously learned strategies. However, reminders to use specific strategies have gradually faded out when the instruction has reached the strategy of questioning and they have totally disappeared when it has reached the last strategy of previewing. Previewing is used as a first step in choosing a short story to read, paraphrase and present to the class.

\section{i. Evaluation}

In this stage, the students are guided to evaluate progress and strategy use. To do this, they are assigned an extensive reading task where they have to select a short story to read, paraphrase and present to the class using the strategy of previewing. Ability to comprehend their reading materials using a combination of top-down, global strategies rather than bottom-up local strategies will indicate their success in strategy use.

When asked to explain in writing how they have dealt with this activity, the students have provided the following answers:

a. All of them have stated that they have skipped unnecessary words and relied on the context to guess the meaning of new words.

b. All of them have declared that since the activity is about paraphrasing, they have used the RAP steps: Reading, then Asking themselves questions about the content of the stories, then Paraphrasing. ( these steps have been described during the presentation of this strategy)

c. All of them have said that they have skimmed through the stories to find out the main ideas.

d. Nine students have declared that they have asked themselves questions about the content for better understanding and remembering.

e. The same nine students have stated that they have scanned the stories to find answers to their own questions. 
Consideration of the students' answers shows that all the reading strategies practiced in this course have been used by the students to varying degrees. All the students have used skipping unnecessary words, guessing the meaning of words from the context, paraphrasing, and skimming. Nine students have used scanning and questioning. It can be claimed then that without using any reminders, the students have been able to use a large number of reading strategies in combination automatically. The fact that the learners have been able to select their own strategies when performing language tasks has therefore facilitated the transition from explicit instruction and guided practice to self-directed strategy use.

\section{The Effect of the Instruction on the Students' Motivation}

To find out if the instruction has succeeded in achieving its objective, which is to increase the students' motivation to read in English by teaching them global reading strategies that deal with general text comprehension rather than word-to-word comprehension, the same questionnaire that was handed in to the students who constitute the focus group prior to the instruction is handed to them again when it is finished. The first question of the first questionnaire (Do you like to learn English?) is omitted from the second one since all the population except for three students have positively answered it and therefore there is no need to check if the instruction has influenced it.

The first question asks the students if they hate to read in English. All the students who are selected to undergo the instruction are those who have declared that they hated to read in English in the first questionnaire. After the instruction is over, it seems necessary to enquire whether it has positively affected their attitude towards this activity. Indeed, all the students who have answered the questionnaire (14 students) have now claimed that they no more hate to read in English. It may be claimed, therefore, that the objective of the instruction has been achieved. These students are asked to justify their answer and nine of them have done so by explaining that this change is due to the strategies they have learned. The five remaining students have simply stated that they like reading and enjoy it without any further justification. Since the instruction on reading strategies is meant to help the non motivated readers to hold more positive attitudes towards this activity, it can be claimed that it has succeeded in doing so.

In the second question, the students are asked if they think that reading in English is boring. Following the same line of the previous question, all the students concerned with the instruction have claimed that they do not think that reading in English is boring. As stated above, the reason that the students have given for feeling bored when reading in this language (question three of the first questionnaire) is their use of ineffective bottom-up reading strategies that focus on meaning of individual words rather than whole text. Readers who deal with texts in this way will lose sight of the whole meaning and therefore will perceive no or little purpose for reading and will ultimately give up. It seems then judicious to claim that the instruction on reading strategies that these students have received has helped them to process texts better so that they do not consider this activity boring anymore. 
The third question asks the students if they have a strong desire to read in English. All the students who have taken part to the instruction have claimed that they have a strong desire to read in English contrary to what they have already stated in answering the same question in the first questionnaire. In fact, desire to learn a language and carry out different activities in that language, namely reading in this particular case, is among the constructs that constitute motivational intensity along with attitudes towards learning that language. The results obtained for this question follow logically those obtained for the previous two questions. Indeed, the fact that the students do not hate to read in English anymore implies that they do not think of this activity as a boring one and this has certainly created in them a desire to read in this language.

The fourth question asks the students if they really enjoy reading in English. Enjoyment in carrying out an activity is a sign of motivated behaviour. All the students have positively answered it. The results obtained for this question reiterate those of the previous one. Desire and enjoyment in doing activities in a foreign language both indicate the existence of intrinsic motivation which is driven by no external forces but only by internal pleasure felt in carrying an activity for its own sake. The students who have all declared that they did not enjoy reading in English in answering the same question in the first questionnaire have now claimed that they really enjoy it. The results obtained for the previous question and the present one, therefore, indicate that the students' motivation to read in English has significantly increased. Therefore, it can be claimed that the instruction they have received on reading strategies has achieved its objectives.

The fifth question asks the students if they tend to give up and not pay attention when they do not understand what they are reading. The Effort exerted in the direction of the experiences or goals a person decides to approach or avoid, as well as attention and persistence are all inseparable components of motivation. Contrary to their answers to this question in the previous questionnaire where the students who were selected for this instruction have declared that they tend to give up and not pay attention when they do not understand what they are reading, the majority of them (92.85\% representing 13 students) have now claimed quite the opposite. The results obtained for this question, then, confirm those of the two previous ones as they all indicate that the students' motivation has significantly increased thanks to the instruction they have received.

The sixth question asks the students if they get anxious when they have to answer questions in their reading class. Language anxiety which manifests itself in a nervous reaction when one has to speak, listen, read or write in the second language (Gardner and McIntyre, 1993), negatively affects levels of motivation. In answering this same question in the first questionnaire, the students who have participated to the instruction have all maintained that they get anxious when they have to answer questions in their reading class. However, in answering it in the present questionnaire, $71.42 \%$ representing 10 out of 14 students have declared that they do not feel anxious anymore when they do so. Their decreased anxiety can be explained by their increased motivation (demonstrated in the previous questions). The fact that four students $(28.57 \%)$ still feel anxious can be attributed to a natural personality trait related to speaking in front of the class rather than to reading itself since even these students have provided answers that indicated an increase in motivation in the previous questions. 
The seventh question asks the students if they feel very much at ease when they have to read in English. In answering it, all the students have declared that they feel very much at ease when they have to read in English, including the four students who have already positively answered the previous question. Concerning the latter, the explanation that can be given is related to the nature of reading itself as a solitary activity. So shy students or those who lack self-confidence or who fear the teacher's reaction feel more at ease when reading alone than when they have to answer questions when all the class is listening. However, on the whole, the results of this question confirm those obtained in the previous ones as they all contradict the negative answers obtained for the same questions in the first questionnaire and point to a significant increase in the students' motivation to read in English.

Analysis of the students' second questionnaire has made it possible to obtain conclusive results about the reading strategy instruction. The first of these is that it has succeeded in changing the students' attitudes towards reading in English. Indeed, they do not hate to read in English anymore and the majority of them have explained this change in attitude by the strategies they have learned during the special instruction (Q1). Consequently, they do not think of reading in English as a boring activity anymore. In the same line, the students have claimed that after the instruction, they have developed desire to read in English (Q3), that they enjoy doing so (Q 4) and that they do not give up anymore when they do not understand what they are reading (Q5). Desire and enjoyment felt when doing activities in a foreign language both indicate the existence of intrinsic motivation which is driven by no external forces other than an external pleasure felt in carrying an activity for its own sake. On the other hand, persistence and attention are regarded as the behavioural manifestations of motivation. Concerning reading class anxiety, the students have revealed through their answers to questions six and seven that it has considerably decreased if not totally disappeared while reading in English. Language learning anxiety in general and reading anxiety in particular decrease as a result of the existence of high levels of motivation.

In the light of the results obtained by means of the field work conducted in this study; the first questionnaire, the instruction and the second questionnaire, some recommendations and pedagogical implication for teachers of Reading Techniques to be used for the sake of creating in the students motivation to read in English are offered. The first of these is a reading syllabus that consists of teaching the strategies that constitute the core of the instruction carried out in the present study. To guarantee that the students make use of all the strategies presented herein (and why not other strategies as well), it is important to assign extensive reading tasks to students and this is also a pedagogical implication of the study. In addition, teachers need to adopt a supportive attitude towards their students and to become facilitators rather than directors since mastering learning strategies in general and reading strategies in particular assumes more independence and responsibility on the part of learners. In this respect, teachers will adopt the roles of diagnosticians, learner trainers, coachers, coordinators, language learners, and researchers. The last pedagogical implication is for teachers to lower levels of anxiety by adopting an encouraging attitude and by creating a more relaxed and healthy atmosphere that makes the students feel confident enough 
to express their difficulties with reading to a teacher who has a less authoritative attitude towards them, is willing to lend an ear to them and who seeks to help them solve their problems.

\section{Conclusion}

Reading is an active process where readers need to interact successfully with the text to make sense of it by means of effective reading strategies. However, the quality of strategies used to process reading materials can largely affect the reader's desire to pursue this task. The present study has departed from the hypothesis that some students lack motivation to read in English due to their employment of inadequate reading strategies, and that if they are trained in the use of more effective ones, then this motivation will subsequently increase. The results obtained after providing the non motivated students with instruction on more effective reading strategies have confirmed these hypotheses and have shown that this instruction has achieved its objectives because it has enhanced in the students motivation to read in English.

\section{The Bibliography}

1. Barnett, M. (1988) Teaching through context: How real and perceived strategy use affect L2 comprehension. The Modern Language Journal, 77,150-162.

2. Barnett, M. (1989) More than Meets the Eye. Englewood Cliffs, NJ: Prentice Hall.

3. Block, E. (1986) The comprehension strategies of second language readers. TESOL Quarterly 20, 436-494. Prentice Hill Regents.

Brown, D. (1994) Principles of language learning and teaching.

5. Brown, H. D. (2001). Teaching by principles: An interactive approach to language pedagogy. Englewood Cliffs, New Jersey: Prentice Hall Regents)

6. Cohen, A. D. (1998). Strategies in learning and using a second language. New York: Longman.

7. Corder, P. (1967) The significance of learners' errors. In international Review of Applied Linguistics. Vol. 5

8. Crookes, G. and Schmidt, R.W. (1991) Motivation: Reopening the research agenda. Language learning, 41,469-512.

9. Dornyei, Z. (1998) Motivation in second and foreign language learning. Language Teaching. 31,3, 117-135. Cambridge University Press.

10. Gardner, R.C., P.C. Smythe, R. Clement and L. Gliksman (1976) Second language acquisition: A social psychological perspective. In Canadian Modern Languages review. $\mathrm{N} 32$.

11. Gardner, R.C. and P.D. McIntyre (1993) A student's contribution to second language learning. Part II: Affective factors. In Language Teaching. 26.1. Cambridge University Press

12. Gascoigne, C., (2008) Independent second language reading as an interdependent process in Lewis ,T. and S. Hurd (eds.) language learning strategies in independent settings (eds). Multilingual Matters.

13. Goodman, K.S. (1979). Reading: A psycholinguistic guessing game. In H. Singer \& R. B. Ruddell (Eds.). Theoretical models and processes of reading (pp. 259-271). Newark, DE: International Reading Association.

14. Grenfell, M. and V. Harris (1999) Modern Languages and Learning Strategies in theory and practice. Routledge. 
15. Harris, V. (1997) Teaching Learners How to Learn. Strategy Training in the ML Classroom. CILT Centre for Information on Language Teaching and Research

16. Hosenfeld, C. (1977) A preliminary investigation of the reading strategies of successful and unsuccessful language learners. System, 5,110-123

17. Karami, H. (2008) Reading Strategies: What are they? eric.ed.gov/?id=ED502937

18.

Kennedy, D. (2003) strategies for developing reading skills: using reading strategies in teaching reading. www.nclrc.org/essentials/reading/stratread.htm

19. King, K. (2008). Reading Strategies. Freely available at: http://www.isu.edu/ kingkath/readstrt.html

20. Lau, K. (2006). Reading strategy use between Chinese good and poor readers: a thinkaloud study. Journal of Research in Reading 29, 383-399.)

21. Macintyre, P.D. and Gardner, R.C. (1989) Anxiety and second language learning: Towards a theoretical classification. In Language Learning. N. 39. Cambridge University Press.

22. Pearson, P. And M. Gallagher (1983) The instruction of reading comprehension. Contemporary Educational Psychology, 8,317-344.

23. Ryan, R.M. and E.L. Deci (20oo) Intrinsic and extrinsic motivation: classic definitions and new directions. Contemporary Educational Psychology. 25, 54-67. Available online at http://www.idealibrary.com

24. Saricoban, A. (2002) Reading Strategies of Successful Readers through the three phase approach. The Reading Matrix 2 (3), 1-13. 